\title{
PENDUGAAN STATUS TROFIK DENGAN PENDEKATAN KELIMPAHAN FITOPLANKTON DAN ZOOPLANKTON DI WADUK SENGGURUH, KARANGKATES, LAHOR, WLINGI RAYA DAN WONOREJO JAWA TIMUR.
}

\author{
ESTIMATION OF TROPHIC STATUS USE PHYTOPLANKTON AND ZOOPLANKTON \\ DENSITY APPROACHMENT AT SENGGURUH DAM, KARANGKATES, LABOR, WLINGI \\ RAYA AND WONOREJO DAM EAST JAVA
}

\author{
Asus Maizar Suryanto H. dan Herwati Umi S. \\ Fakultas Perikanan dan Ilmu Kelautan Universitas Brawijaya \\ Jl. Veteran, Malang 65145 \\ Telp. 0341-553512
}

\begin{abstract}
The aim of these study was to know plankton (phytoplankton and zooplankton spesies and density at Sengguruh dam, Karangkates, Lahor, Wlingi Raya and Wonorejo, and to estimated trophic status these dams use phytoplankton and zooplankton density approachment. These study used descriptive methode with survey technic. Data wich is taken from each dam is taken from four different station that suggested the representated dam condition. The result showed according to the range phytoplankton density: at Karangkates between 144-236 ind/ml is clustered as oligotrophic, the range phytoplankton density at sengguruh between $217-313 \mathrm{ind} / \mathrm{ml}$ is clustered as oligotrophic. At Lahor dam between 5.356$12.704 \mathrm{ind} / \mathrm{ml}$ is clustered as mesotrophic, at Wlingi Raya dam between $74-1480 \mathrm{ind} / \mathrm{m}^{\prime}$ is clustered as mesotrophic to eutrophic, while at Wonorejo dam between $48-288 \mathrm{ind} / \mathrm{ml}$ is clustered as oligotrophic waters. According to the range zooplankton density: at Karangkates dam between 28.153-132.056 ind/lt is clustered as mesotrophic, Lahor dam between 4.996-14.275 ind/lt is clustered as mesotrophic, Wlingi Raya dam between 623-3.114 ind/lt is clustered as oligotrophic to mesotrophic, and Wonorejo dam between 2-6 ind/lt is clustered as mesotrophic. The differences of estimation result of trophic level at each dam according to phytoplankton and zcoplankton density data is showed that dam ecosystem was imbalance
\end{abstract}

Keywords : trophic status, phytoplankton, zooplankton, dam

\section{Pendahuluan}

Untuk memenuhi ketersediaan air salah satu metode penyediaan sumberdaya air yang selama ini dikenal adalah bendungan atau waduk (Munir, 2003). Waduk adalah perairan berhenti atau menggenang yang terjadi karena dibuat oleh manusia dengan cara membendung sungai, kemudian airnya disimpan. Pembuatan waduk pada umumnya bertujuan untuk sumber air minum, PLTA, pengendali banjir, pengembangan perikanan darat, irigasi dan pariwisata. waduk yang demikian disebut waduk serba guna (Ewusie, 1990).

Sumberdaya perairan di waduk selain ikan dan tanaman air juga terdapat biota lain yaitu salah satunya adalah plankton. Plankton adalah organisme mengapung yang pergerakannya tergantung arus (Odum, 1993).

Plankton merupakan suatu organisme yang berukuran kecil yang hidupnya terombangambing oleh arus perairan. Organisme ini terdiri dari mikroorganisme yang hidupnya sebagai hewan (zooplankton) dan tumbuhan (fitoplankton) (Sachlan, 1972).

Adapun waduk-waduk yang terdapat di Jawa Timur di antaranya adalah waduk Sengguruh, Karangkates, Lahor, Wlingi Raya dan Wonorejo, dimana waduk-waduk tersebut merupakan beberapa waduk yang menampung aliran sungai Brantas.

Pada awal penggenangan, waduk akan mengalami pengayaan nutrien (nutrient enrichment) yang disebabkan masukan bahan organik maupun anorganik. Adanya beban masukan baik organik maupun anorganik dapat mengakibatkan berubahnya komunitas plankton di perairan waduk. Dalam manfaatnya sebagai kawasan perikanan darat maka peran plankton sangat penting dalam meningkatkan produktifitas perairan di perairan waduk. Dengan mengetahui kelimpahan dan komposisi fitoplankton maupun zooplankton serta pengukuran kualitas air di perairan waduk, diharapkan dapat memberi informasi mengenai kondisi lingkungan perairan waduk termasuk 
status trofiknya (tingkat kesuburannya), sehingga dapat mempermudah pengelolaan serta pengembangan waduk tersebut di masa mendatang.

Adapun tujuan dari penelitian ini antara lain: untuk mengetahui jenis-jenis dan kelimpahan plankton (fitoplankton dan zooplankton) di waduk Sengguruh, Karangkates, Lahor, Wlingi Raya dan Wonorejo, serta menduga status trofik waduk tersebut dengan pendekatan kelimpahan fitoplankton dan zooplankton.

\section{Materi dan Metode Penelitian}

Metode dalam Penelitian ini adalah deskriptif. Sifat umum dari bentuk metode deskriptif yaitu mengumpulkan, menyusun, menganalisa, dan menafsirkan data kemudian diadakan klasifikasi atau dibandingkan antara satu kelompok data dengan kelompok data yang lain. Dengan Teknik Survei dan Kajian Pustaka pada umumnya melakukan pengumpulan data sejumlah unit (satuan) individu dalam waktu yang bersamaan (Marzuki, 1983). Data Primer yang diambil adalah data yang diambil melalui observasi langsung di lapang pada waduk Sengguruh, Karangkates, Lahor, Wonorejo dan Waduk Wlingi Raya.

Sampel Plankton yang diambil dari waduk tersebut kemudian di identifikasi jenisnya, yang berpedoman pada: Prescott (1979) dan Sachlan (1972). Untuk perhitungan kelimpahan plankton berpedoman pada Nollet (2000). Pengamatan dan identifikasi plankton yang ditemukan dilakukan di laboratorium Ilmu-Ilmu Perairan Fakultas Perikanan dan Ilmu Kelautan Universitas Brawijaya. Untuk menduga status trofik berdasarkan kelimpahan fitoplankton berpedoman pada Landner (1978) yaitu:

- Perairan Oligotrofik merupakan perairan yang tingkat kesuburan rendah dengan kelimpahan fitoplankton berkisar antara 0 $2000 \mathrm{ind} / \mathrm{ml}$.

- Perairan Mesotrofik merupakan perairan yang tingkat kesuburan sedang dengan kelimpahan fitoplankton berkisar antara $2000-15.000 \mathrm{ind} / \mathrm{ml}$.

- Perairan Eutrofik merupakan perairan yang tingkat kesuburan sedang dengan kelimpahan fitoplankton berkisar antara > $15.000 \mathrm{ind} / \mathrm{ml}$

Untuk menduga status trofik berdasarkan kelimpahan zooplankton berpedoman pada (Goldman and Horne, 1994), yaitu:

- Oligotrofik yaitu perairan tersebut mempunyai tingkat kesuburan rendah dengan kelimpahan zooplankton kurang dari $1 \mathrm{ind} / \mathrm{lt}$,

- Mesotrofik yaitu perairan yang mempunyai tingkat kesuburan sedang dengan kelimpahan zooplankton antara 1-500 ind/lt,

- Eutrofik yaitu perairan yang mempunyai tingkat kesuburan tinggi dengan kelimpahan zooplankton lebih dari 500 ind/lt.

Stasiun Pengambilan sampel Pada masingmasing waduk adalah Sebagai Berikut:

A. Stasiun pengamatan di waduk Sengguruh:

- Stasiun 1 merupakan daerah aliran masukan air dari sungai Brantas

- Stasiun 2 merupakan daerah aliran masukan air dari sungai Lesti

- Stasiun 3 merupakan daerah tengah waduk (pertemuan antara sungai Brantas dan sungai Lesti)

- Stasiun 4 merupakan daerah pengeluaran waduk

B. Stasiun pengamatan di waduk Karangkates:

- Stasiun 1 merupakan daerah tempat air keluar

- Stasiun 2 merupakan daerah tempat air masuk dari sungai brantas

- Stasiun 3 merupakan daerah tengah-tengah Waduk

- Stasiun 4 merupakan daerah dekat dengan persawahan yang mendapat masukan limbah dari pupuk pertanian

C. Stasiun pengamatan di waduk Lahor:

- Stasiun 1 merupakan daerah inlet yaitu daerah masuknya air dari aliran sungai Leso

- Stasiun 2 merupakan daerah tempat air keluar ke Waduk Sutami (Karangkates)

- Stasiun 3 merupakan daerah dekat dengan pemukiman penduduk yang mendapat masukan berupa limbah domestik.

- Stasiun 4 merupakan Daerah tengah dari waduk

D. Stasiun pengamatan di waduk Wonorejo:

- Stasiun 1, merupakan daerah pariwisata

- Stasiun 2 merupakan daerah muara sungai yang mendapat masukan dari aliran sungai Putih, Wangi dan Bodeng.

- Stasiun 3 merupakan daerah outlet waduk

E. Stasiun pengamatan di waduk Wlingi Raya:

- Stasiun 1 merupakan daerah inlet dari kali Brantas yang merupakan daerah aliran dari kawasan pertanian dan perkebunan.

- Stasiun 2 merupakan daerah inlet dari kali Jari yang merupakan daerah aliran dari kawasan pemukiman.

- Stasiun 3 merupakan daerah tengah waduk.

- Stasiun 4 merupakan daerah outlet (daerah keluaran air dari waduk) 


\section{Hasil dan Pembahasan}

Waduk Karangkates

a. Fitoplankton

Berdasarkan data Komposisi jenis dan kelimpahan Fitoplankton di waduk Karangkates yang ditemukan terdiri dari Filum Chlorophyta terdiri dari genus: Chlorella,Chlorochytrium, Chloteriopsisi, Crucigena, Dactylococcus, Diogenesis, Euastropsis, Genicularia, Kenthospaera, Monostroma, Tetraedon, Filum Chrysophyta terdiri dari genus : Chlorogibba, Chlorocoster, Chroomonas, Chrysopyxis, Chrisidiastrum, Dioxys, Goniochloralis, Tetrasporosis, Tetragonodium, Tribonema, Vesicle. Filum Cyanophyta terdiri dari genus: Bacillasiphon, Borzia, Holopedium, Microcoleus, Microcystis, Oscilatoria, Raphidiopsis, Spirulina, Merismepedia. Filum Euglenophyta terdiri dari satu genus yaitu Phagus, sedangkan Filum Phyrrophyta terdiri dari dua genus yaitu Ceratium dan Perididinium.

Filum Cyanophyta pada setiap stasiun relatif lebih tinggi dibandingkan dengan phyllum yang lainnya. Phyllum Cyanophyta yang ditemukan dari hasil pengamatan sampel sebanyak 8 genus yang didominasi oleh Microcystis. Sachlan (1972) mengatakan Microcystis berbentuk bulat kecil dan hidup berkoloni. (Richmond, 2005) menyatakan melimpahnya jumlah phyllum Cyanophyta karena Filum ini mampu beradaptasi dengan keadaan yang kurang menguntungkan $\left(\mathrm{CO}_{2}\right.$ rendah, suhu rendah atau terlalu tinggi, dan cahaya kurang). Lebih lanjut tingginya Cyanophyta disebabkan saat pengambilan sampel dilakukan saat intensitas cahaya matahari belum terlalu tinggi. Menurut Goldman and Horne (1994) pada saat pagi hari cyanophyta akan mengapung kepermukaan perairan, demikian juga pada saat malam hari. Gerakan vertikal dari cyanophyta tersebut karena memiliki gas vacuola.

Sedangan rata - rata kelimpahan fitoplankton dari stasiun 1 sampai stasiun 4 di Waduk Karangkates, berkisar antara 144 - 236 ind $/ \mathrm{ml}$. Berdasarkan kelimpahan fitoplankton menurut Landner (1978) maka perairan waduk karangkates tergolong perairan Oligothrofik yaitu perairan yang mempunyai tingkat kesuburan yang rendah.

b. Zooplankton

Berdasarkan data Komposisi jenis dan kelimpahan Zooplankton di waduk Karangkates yang ditemukan dari kelas Arthropoda genus yang ditemukan yaitu Daphnia, Cyclop, Nauplis, Zoea. Kelas Rotifera genus yang ditemukan adalah Branchionus, Keratela, Tricocerca, Diurella, dan Asplanchna.

Zooplankton terbanyak di Waduk Karangkates (lampiran 2) adalah Filum Rotifera (Brachionus) dan yang paling sedikit ditemukan adalah Filum Arthropoda (Cyclop). Hal ini diduga karena Rotifera memiliki karakteristik yang banyak ditemukan di perairan subur. (Sachlan,1972), Rotifera merupakan konsumer, ada yang merupakan herbivora maupun karnivora merupakan zooplankton sejati, distribusinya meluas secara kosmopolit, beberapa spesies tersebar di seluruh dunia. Rotifera biasa terdapat di perairan yang di pupuk dengan pupuk organik.

Berdasarkan data kelimpahan zooplankton dari stasiun 1 sampai stasiun 4 di Waduk Karangkates berkisar 28,153 - 132,056 ind/lt, maka perairan ini termasuk perairan yang mempunyai kesuburan sedang (mesotrofik). Sesuai dengan pernyataan (Goldman and Horne, 1994) bahwa perairan Mesotrofik yaitu Perairan yang mempunyai tingkat kesuburan sedang dengan kelimpahan zooplankton berkisar antara $1-500 \mathrm{ind} / \mathrm{lt}$ atau $1000-500.000 \mathrm{ind} / \mathrm{ml}$.

Waduk Sengguruh

a. Fitoplankton

Berdasarkan data Komposisi jenis dan kelimpahan Fitoplankton di waduk Sengguruh yang ditemukan dari Filum Chlorophyta, genus yang ditemukan adalah Nanochloris, Genicularia, Hydrodiction, Planktospaeria, Netrium, Treubaria, Asterococcus, Scenedesmus, Chlosarcina, Chodatella, Chlosterium. Filum Chrysophyta terdiri dari genus : Pinnularia, Tabellaria, Diatoma, Navicula, Actinella, Synedra, Diploneis, Coscinodiscus, Nitzschia, Cocconeis, Achnanthes, Stauroneis, Eunotia, Hanzschia, Gyrosigma, Frustulia, Surirella, Fragillaria, Cymbella, Coloneis, Chaetoceros, Ephytemia, Neidium, Amphora, Terpsinoe, Amphileura, Melosira, Skeletonema, Gomphonema. Filum Cyanophyta ditemukan genus: Anabaena, Ocillatoria, Gloeothece, Phormidium, Arthrospira.

Hasil Penelitian diperoleh bahwa fitoplankton yang ditemukan di dominasi Filum Chrysophyta. Hal ini menurut Sachlan (1972) karena dinding sel Chrysophyta sangat keras dan tidak dapat membusuk atau larut dalam air karena terdiri dari $100 \%$ silikat. Hal tersebut memungkinkan kelompok tersebut lebih dapat bertahan hidup dibanding kelompok lain. Arfiati (1995) menambahakan, Filum Chrysophyta cenderung lebih aktif dalam memanfaatkan nutrien bila dibandingkan dengan jenis Filum 
lain, sehingga Filum ini lebih banyak ditemukan. Sedangkan Filum Cyanophyta menjadi Filum dengan kelimpahan terendah. Rendahnya kemelimpahan Cyanophyta menurut Belvher dan Swale (1976) dalam Suryanto (2005) karena fitoplankton dari kelompok ini dapat tumbuh dari zat hara anorganik dalam perairan yang rendah karena kebutuhan minimal akan zat hara anorganik tersebut jauh lebih rendah dari lainnya.

Sedangkan kelimpahan rata - rata fitoplankton dari stasiun 1 sampai stasiun 4 yang ditemukan di Waduk Sengguruh berkisar 217 - $313 \mathrm{ind} / \mathrm{ml}$. Menurut (Landner, 1978) perairan waduk Sengguruh tergolong perairan oligotrofik.

\section{Waduk Lahor}

a. Fitoplankton

Berdasarkan data komposisi jenis dan kelimpahan fitoplankton di waduk Lahor ditemukan 2 Filum yaitu Filum Chlorophyta, Cyanophyta dan Chrysophyta. Untuk fitoplankton yang tergolong dalam Filum Chlorophyta diwakili oleh genus Ankistrodesmus, Sphyrogyra, Coelastrium, Oedogonium, Chlorella, Ulothrix, Chlorosarcinopsis. Sedangkan untuk Filum Cyanophyta yaitu genus Spirullina, Oscilatoria, Anacystis, Microcystis, Nostoc, Anabena, Dactylocopsis, Lyngbya dan untuk Filum Chrysophyta yaitu genus Melosira, Stycochrysis, Fragilaria, Tabelaria, Nitzchia, Hemiaulus, Hydrosera, Cyclotella dan Asterionella.

Kelimpahan fitoplankton yang ditemukan di Waduk Lahor menunjukkan perbedaan antara stasiun satu dengan stasiun lainnya. Penyebab perbedaan antara jumlah plankton antara tiap lokasi antara lain diduga disebabkan:

- Sifat plankton yang sering menggerombol karena pengaruh angin dan arus menyebabkan daerah penyebaran tidak merata dalam pengambilan sampel.

- Adanya predator pada suatu lokasi sehingga suatu saat diperairan kaya plankton tetapi pada waktu lain miskin plankton.

- Karena arah angin, hal ini menyebabkan plankton terbawa pada arah angin tertentu dalam suatu waduk.

Menurut Landner (1978), kesuburan perairan berdasarkan kelimpahan fitoplankton dibagi menjadi :

- Oligotrofik : 0 - $2000 \mathrm{ind} / \mathrm{ml}$

- Mesotrofik : $2000-15000 \mathrm{ind} / \mathrm{ml}$

- Eutrofik : > $15000 \mathrm{ind} / \mathrm{ml}$

Berdasarkan kelimpahan fitoplankton, perairan waduk Lahor yang mempunyai kelimpahan rata - rata yang berkisar antara 5,356 - 12,704 individu/liter termasuk dalam kategori perairan Mesotrofik yaitu perairan yang dapat dikatakan mempunyai tingkat kesuburan sedang. Pengambilan sampel dilakukan pada pukul $09.00-12.00$ WIB dimana aktifitas fitoplankton untuk berfotosintesis optimal sehingga hasil yang diperoleh dalam pengukuran kelimpahan juga besar. Ketika berada di permukaan fitoplankton melakukan proses fotosintesis dengan bantuan cahaya matahari (Odum, 1971).

b. Zooplankton

Berdasarkan data Komposisi jenis dan kelimpahan Zooplankton di waduk Lahor, didapatkan 2 Kelas yaitu Kelas Arthropoda dan Rotifera. Untuk Kelas Rotifera diwakili oleh Keratella, Kellicotia, Brachionus, Trichocerca, Diurella dan Chromogaster. Zooplankton yang tergolong dalam Kelas Arthropoda yang ditemukan di waduk Lahor diwakili oleh Cyclops, Cypris, Dapnia, Diaptomus, Trichocerca, dan Nauplius.

Menurut pengklasifikasian oleh Goldman and Horne (1994) perairan Waduk Lahor dengan kelimpahan zooplakton rata-rata berkisar antara 4,996 -14,275 individu/liter merupakan perairan yang mesotrofik yaitu perairan yang dapat dikatakan perairan yag mempunyai tingkat kesuburan yang sedang.

Waduk Wlingi Raya

a. Fitoplankton

Dari hasil pengamatan jenis fitoplankton yang ditemukan di Waduk Wlingi Raya terdiri dari 6 filum yaitu; (1) Cyanophyta hanya terdiri dari satu genus yaitu Holopedium; (2) Chlorophyta terdiri dari 33 genus yaitu Dermatophyton, Characiochloris, Gloetila, Roya, Xanthidinium, Scotielia, Zygogonium, Prasinocladus,Lobocystis, Chlorococcum, Gloetaenium, Helicodictyon, Docidium, Pleurogaster, Pandorina, Raphidonema, Entransia, Hormidiopsis, Keriochlamys, Haematococcus,Hazenia, Pleurocodiscus, Dermatophyton,Spirogyra, Apatococcus, Excentrospaera,Asterococcus, HyalothecaMono stroma, Spaeroplea, Netrium, Gonatozygon, dan Pachycladon; (3) Chrysophyta (Bacillariaceae) terdiri dari 3 genus yaitu Brebissonia, Clamydomyxa, dan Chrysostephanospaera; (4) Phyrrophyta (dinoflagellata) terdiri dari 3 genus yaitu Gymnodinium, Chroomonas, dan Hypnodinium; (5) Euglenophyta terdiri dari dari 2 genus yaitu Euglenamorpha dan Euglena; (6) Rhodophyta terdiri dari 2 genus yaitu Chroothece dan Nitzschia. 
Waduk Wlingi Raya berdasarkan klasifikasi tingkat kesburannya Landner (1978), mempunya kelimpahan rata-rata berkisar antara 74-1480 individu/ml sehingga dikategorikan perairan eutrofik.

b. Zooplankton

Dari hasil pengamatan jenis zooplankton yang ditemukan di Waduk Wlingi Raya ditemukan dua kelas, yaitu kelas Rotifera genus yang ditemukan adalah Keratella, Monostylla, dan branchionus. Sedangkan kelas berikutnya adalah Protozoa, genus yang ditemukan adalah Lacrymaria, Halteria, dan Stylonichia.

Secara keseluruhan Waduk Wlingi Raya di dominasi oleh Kelas Protozoa yaitu dari genus Halteria. Kelompok ini melayang dalam air, sessile, hidup tidak tergantung dengan organisme lain, tersebar di habitat air tawar, laut atau estuari bahkan sampai pada habitat teresterial. Khususnya pada genus Halteria, dapat berpindah seperti melompat dalam air (Google, 2009). Sehingga dapat menghindar dari serangan predator, Sedangkan Filum Rotifera mempunyai kelimpahan terendah. Menurut Fogg and Thake (1987), Filum ini mempunyai jumlah sel yang tidak terlalu bervariasi seperti organisme hewan lainnya. Filum Rotifera dijuluki 'minor Filum' karena jumlah spesiesnya kurang dari 2000 spesies.

Kelimpahan rata - rata zooplankton di waduk wlingi Raya berkisar 0,623 - 3,114 ind/lt, sehingga menurut Goldman dan Horne, (1994) perairan waduk tersebut tergolong perairan oligotrofik menuju mesotrofik atau mempunyai tingkat kesuburan rendah sampai sedang.

Waduk Wonorejo

a. Fitoplankton

Komposisi fitoplankton di waduk Wonorejo selama penelitian terdiri dari 3 phyllum, yaitu Chlorophyta, Chrysophyta dan Cyanophyta. Jumlah genus yang ditemukan selama penelitian ada 39 genus. Phyllum dengan jumlah genus tertinggi adalah phyllum Chlorophyta yang terdiri dari 24 genus antara lain Ankistrodesmus, Bracteacoccus, Chlorella, Closterium, Closteriopsis, Cosmarium, Dactylococcus, Desmatractum, Chlamydomonas, Dyctyosphaerium, Euastridium, Genicularia, Gloeotanium, Gonatozygon, Hydrodictyon, Microspora, Monostroma, Mougeotiopsis, Pachycladon, Pectodictyon, Staurastrum, Tetradesmus, Tetraedron dan Volvox. Phyllum Chrysophyta dengan 9 genus antara lain Asterionella, Centronella, Chlamydomyxa, Diachros, Diceras, Dinobryon, Navicula, Tetradriella dan
Tribonema. phyllum Cyanophyta yang terdiri dari 6 genus antara lain Aphanizonemon, Borzia, Dactylococcopsis, Holopedium, Sacconema dan Spirulina. Untuk phyllum Phyrrophyta dan Euglenophyta tidak ditemukan. Menurut Sachlan (1972) jenis ini lebih banyak ditemukan di kolam - kolam yang banyak mengandung bahan organik atau kemungkinan jenis ini tidak ikut tersaring dalam plankton net pada waktu pengambilan air sampel.

Dari data di atas, diketahui bahwa nilai kelimpahan fitoplankton di waduk Wonorejo berkisar antara $48-288$ ind $/ \mathrm{ml}$. Nilai kelimpahan tertinggi didapatkan pada minggu keempat di stasiun 2 (muara sungai) sebesar 288 ind $/ \mathrm{ml}$, hal ini diduga disebabkan karena kandungan nutrient terlarut dan kondisi lingkungan mendukung pertumbuhan, selain itu kondisi lingkungan yang mendukung dimana suhunya berkisar antara $28{ }^{0} \mathrm{C}$. Menurut Prescod (1973) fitoplankton di daerah tropis (panas) biasanya tumbuh dengan cepat, apabila cahaya matahari meningkat dan kebutuhan nutrient terpenuhi, pertumbuhannya kontinyu bahkan bisa mencapai bloom.

Nilai kelimpahan fitoplankton terendah didapatkan pada minggu kedua di stasiun 3 (outlet) kedalaman $60 \mathrm{~cm}$ sebesar $48 \mathrm{ind} / \mathrm{ml}$, hal ini diduga disebabkan kondisi lingkungan yang tidak mendukung pertumbuhan karena stasiun ini merupakan saluran outlet waduk sehingga fitoplankton secara pasif mengikuti arus air dan terlimpas keluar waduk disamping itu di daerah outlet lebih dalam dibandingkan stasiun lainnya sehingga memungkinkan unsur hara dari dasar untuk mencapai permukaan tempat fitoplankton hidup sangat kecil. Boney (1975) Hal tersebut karena fitoplankton tidak mempunyai mekanisme pertahanan pada arus yang kuat. Pada arus yang cepat fitoplankton akan cenderung menjadi alga yang sesile atau menempel di dasar perairan atau benda lainnya di perairan.

Berdasarkan kelimpahan rata-rata waduk Wonorejo mempunyai kelimpahan fitoplankton antara 48 - 288 ind/ml. Menurut Landler (1978) perairan waduk Wonorejo tergolong perairan oligotrofik yaitu perairan yang mempunyai tingkat kesuburan yang rendah

\section{b. Zooplankton}

Komposisi zooplankton yang ditemukan dari hasil Penelitian terdiri dari 3 Filum, yaitu Arthropoda, Rotifera dan Protozoa. Jumlah genus yang ditemukan selama penelitian adalah 10 genus. Filum dengan jumlah genus tertinggi adalah Filum Rotifera yang terdiri dari 5 genus (Asplanchna, Brachionus, Diurella, Euclanis dan Keratella), kemudian Filum Arthropoda 
dengan 4 genus (Cyclop, Diaptomus, Nauplii dan Zoea) dan Filum Protozoa yang terdiri dari 1 genus (Bodo).

Jika dilihat dari kelimpahan zooplankton yang hidup di perairan Waduk Wonorejo selama penelitian berkisar antara 2 ind/lt - 16. ind/lt, maka perairan ini termasuk perairan yang mempunyai tingkat kesuburan sedang(mesotrofik) Goldman dan Horne (1994).

Hasil penelitian secara keseluruhan menunjukkan tingkat trofik perairan berdasarkan kelimpahan fitoplankton dan kelimpahan zooplankton pada masing-masing waduk menunjukkan hasil yang berbeda, hal tersebut diduga disebabkan:

- Adanya predasi, atau pemangsaan fitoplankton oleh zooplankton

- Adanya migrasi secara vertikal oleh fitoplankton maupun zooplankton saat pengamatan.

- Keterbatasan unsur hara sebagai nutrisi pertumbuhan fitoplankton dan keberadaan detritus organik yang merupakan makanan lain dari zooplankton

\section{Kesimpulan}

Hasil penelitian menunjukkan : (1). Kelimpahan fitoplankton di Waduk Karangkates, berkisar antara 144 - 236 ind/ml, maka dapat dikatakan perairan Waduk Karangkates yang mempunyai tingkat kesuburan yang rendah (Oligothrofik). Kelimpahan zooplankton di Waduk Karangkates berkisar 28,153 - 132,056 ind/lt, maka perairan ini termasuk perairan yang mempunyai kesuburan sedang (mesotrofik) (2). Kelimpahan rata - rata fitoplankton yang ditemukan di Waduk Sengguruh berkisar 217 $313 \mathrm{ind} / \mathrm{ml}$, sehingga perairan Waduk Sengguruh tergolong perairan oligotrofik. (3). Berdasarkan kelimpahan fitoplankton, perairan waduk Lahor yang mempunyai kelimpahan rata - rata yang berkisar antara 5.356 - 12.704 individu/ml termasuk dalam kategori perairan yang Mesotrofik. Sedangkan menurut kelimpahan zooplankton maka perairan Waduk Lahor yang mempunyai kelimpahan rata-rata yang berkisar antara 4,996 - 14,275 individu/lt merupakan perairan yang mesotrofik (4). Kelimpahan rata-rata fitoplankton di Waduk Wlingi Raya berkisar antara 74-1.480 ind/ml sehingga waduk Wlingi Raya termasuk ke dalam perairan yang mesotrofik menuju eutrofik. Sedangkan kelimpahan rata - rata zooplankton di waduk wlingi Raya berkisar 623 - 3,114 ind/lt maka dapat perairan oligotrofik menuju mesotrofik (5). Nilai kelimpahan fitoplankton di waduk Wonorejo berkisar antara
48 - $288 \mathrm{ind} / \mathrm{ml}$ maka perairan waduk Wonorejo tergolong perairan oligotrofik. Sedangkan kelimpahan zooplankton yang hidup di perairan Waduk Wonorejo berkisar antara 2 ind/lt - 16 ind/lt, maka perairan ini termasuk perairan yang mempunyai tingkat kesuburan sedang (mesotrofik).

Berdasarkan hasil penelitian dapat disarankan perlunya upaya manajemen terutama bagi waduk yang mengalami eutrofikasi berdasarkan kelimpahan fitoplankton maupun zooplankton. Langkah manjemen tersebut diantaranya perlu tindakan peningkatan kesadaran masyarakat dan kalangan industri yang membuang limbahnya kesungai yang bermuara ke waduk.

\section{Daftar Pustaka}

Arfiati, D. 1995. Survey Pendugaan Kepadatan Fitoplankton sebagai Produktivitas Primer di Rawa Bureng, Desa Sukosari, Kecamatan Gondanglegi, Kabupaten Malang, Jawa Timur. Fakultas Perikanan Universitas Brawijaya. Malang

Boney, A.D. 1975. Phytoplankton. Institute Of Biology Study. Crane. Russak. New York. USA.

Ewusie,1990. Pengantar Ekologi Tropika. Institut Teknologi Bandung. Bandung

Fogg, G.E., and B. Thake. 1987. Algal Culture and Phytoplankton Ecology. 3d ed. University of Wisconsin Press. Madison

Goldman CR., and Horne AJ., 1994, Limnology, Mc. Graw Hill Book Co. USA

Jasa tirta. 2006. Waduk Karangkates. http://www.jasatirta1.go.id. Diakses tanggal 20 Juli 2007

Landner, 1978. Eutrophication of lakes. Analysis Water and Air Pollution Research Laboratory Stockholm. Sweden

Nollet LML.,2000. Handbook Of Water Analysis. Marcel Dekker,Inc. USA

Noughton, Mc, S. J dan Wolf, L. L. 1998. Ekologi Umum. Gadjah mada University Press. Yogyakarta

Marzuki, 1983. Metodologi Penelitian. PT Gramedia Pustaka Utama. Jakarta.

Munir, M. 2003. Geologi Lingkungan. Bayu Media. Malang

Odum, E.P, 1971. Fundamental of Ecology. WB Sounders Co. Ltd Japan Company. Tokyo.

Prescod, M.B. 1973. Investigation of Rational Effluent and Stream Standarts for 
Tropical Countries. ASEAN Institute of Technology. Bangkok

Richmond, A, 2005., Microalgal Culture,

Biotechnology and Applied Phycology,

Blackwell Publishing

Sachlan, M. 1972. Planktonologi. Direktorat Jendral Perikanan. Departemen Pertanian. Jakarta

Sudaryanti, S. 2005. Eutrofikasi dan Metode Rehabilitasinya. Fakultas Perikanan Universitas Brawijaya. Malang
Suryanto, A. M. 2005. Kemelimpahan Kelas Fitoplankton pada Budidaya Udang Galah (Macrobrachium rosenbergii) dengan Sistem yang Berbeda. Jurnal Penelitian Perikanan Vol. 08 No 1 FPIK-UB. Malang

Wikipedia. 2009. Introduction to the Rotifera. www.google.com. Diakses pada tanggal 15 Januari 2009. 